\title{
Perencanaan dan Pelaksanaan Pembelajaran Koperatif Tipe Investigasi Kelompok untuk Meningkatkan Efektivitas Pembelajaran Fisika Kelas X: Penelitian Tindakan Kelas
}

\author{
Septian Efendi ${ }^{\text {a) }}$, Irwan Koto ${ }^{\text {b) }}$ \\ Program Studi Pendidikan Fisika, Jurusan PMIPA FKIP, Universitas Bengkulu-3837A

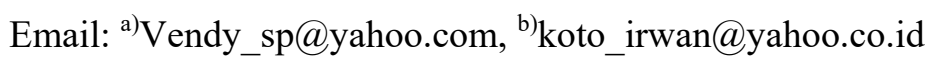

\begin{abstract}
This paper addresses how to plan and implement the Group Investigation (GI) in an attempt to enhance the efectiveness of physics learning. It reports research with 30 Year-10 high school students studying temperature and heat transfer, during which the researchers employed a participatory action research approach. The research tools used to achieve the research aim were the written test, observations of teacher and student activities. To assess the students' performance, a written test was administered following the validity and realibility of item test. Of 24 items was tried out, 18 items were valid with Cronbach Alpha reliabilities $>0.70$. The teacher roles in learning activities were evaluated by using the classroom observation protocols conducted by three observers with ICC coefficient varrying above 0.71 to below 0.54. The results suggest that the GI instructional strategy can contribute positively to the efectiveness of physics learning (1) in terms of students' performance on the test, and (2) by adaptating stage 1 (identifying the topics) and stage 2 (planning the investigation).
\end{abstract}

Keywords: Group investigation, the efectivenss of physics learning.

\begin{abstract}
Abstrak
Penelitian ini bertujuan untuk meningkatkan efektifitas pembelajaran fisika di kelas $X_{d}$ SMA Negeri 6 Kota Bengkulu melalui perencanaan dan pelaksanaan pembelajaran koperatif tipe investigasi kelompok. (GI) yang melibatkan 30 siswa dan tiga pengamat. Penelitian tindakan partisipatori dilaksanakan dengan indikator efektifitas pembelajaran adalah daya serap dan ketuntasan belajar. Instrumen penelitian terdiri dari tes hasil belajar serta lembar observasi guru dan siswa. Melalui analisis butir tes, 18 butir tes diketahui valid dengan koefisien Alpha Cronbach $>0,70$. Lembar observasi guru dan siswa digunakan untuk menentukan efektivitas pembelajaran dengan koefisien ICC antar tiga pengamat $(0,54)$ siklus I dan koefisien ICC $(0,71)$ siklus II. Validasi internal dilakukan melalui Triangulasi. Simpulan menunjukkan bahwa model pembelajaran GI dapat meningkatkan efektifitas pembelajaran fisika: (1) ditinjau daya serap dan ketuntasan belajar; dan (2) melalui modifikasi model pembelajaran koperatif tipe GI pada tahap menetapkan topik permasalahan (Tahap-1) dan merencanakan penyelidikan (Tahap-2).
\end{abstract}

Kata-kata kunci: Investigasi kelompok, Efektivitas pembelajaran fisika. 


\section{PENDAHULUAN}

Peningkatan mutu proses pembelajaran di sekolah dapat diupayakan melalui peningkatan partisipasi aktif siswa dalam pembelajaran. Partisipasi tersebut diharapkan dapat meningkatkan prestasi belajar siswa. Untuk mewujudkan tujuan tersebut, peran guru tidak dapat diabaikan. Guru dapat dianggap sebagai penentu keberhasilan pembelajaran karena guru berperan sebagai perencana dan pelaksanaan proses pengajaran (Rusma 2011). Oleh sebab itu, peningkatan mutu perencanaan dan pelaksanaan pengajaran dapat menentukan efektivitas pembelajaran pada materi pelajaran tertentu.

Salah satu strategi yang dapat dilakukan untuk meningkatkan peran aktif siswa dalam belajar fisika adalah dengan mengetahui minat siswa belajar dan mengetahui bagaimana siswa belajar. Dari angket singkat yang disebarkan di kelas Xd SMANegeri 6 Kota Bengkulu diketahui $43 \%$ siswa menyatakan "pelajaran fisika membosankan" namun 53\% siswa lebih "senang mengerjakan soal-soal secara berkelompok". Disamping itu, hasil wawancara dengan guru terungkap bahwa hanya $25 \%$ siswa yang berperan aktif di kelas seperti bertanya atau mengajukan pendapat. Permasalahan belajar fisika diatas diperkuat dengan hasil pengamatan di kelas. Kecenderungan guru memilih dan menerapkan pengajaran fisika secara klasikal dengan metode ekspositori dan latihan soal mungkin salah satu penyebab pelajaran fisika kurang menarik dan menjadi sulit khususnya bagi siswa-siswa yang kurang berpartisipasi aktif. Studi dokumentasi nilai ujian harian dan UTS menunjukkan bahwa siswa yang kurang berprestasi (nilai<rata-rata kelas) cenderung berpartisipasi pasif (duduk, mendengar, mencatat).

Oleh sebab itu, perlu dilakukan suatu tindakan yang terencana dan dilaksanakan secara konsisten agar partisipasi aktif siswa dalam pembelajaran fisika dapat ditingkatkan yang pada akhirnya hasil belajar siswa dapat memenuhi target capaian pembelajaran. Untuk itu, seorang guru seharusnya dengan tepat menentukan dan menerapkan suatu strategi pembelajaran. Salah satu strategi pembelajaran koperatif yang dapat menumbuhkan partisipatif aktif siswa dalam belajar adalah model pembelajaran koperatif tipe Investigasi Kelompok (GI) (Shachar \& Fischer 2004). Selanjutnya Mitchell, Montgomery, Holder and Start (2008) menyatakan bahwa "Group investigation allows students to be directly involved in how they obtain knowledge; they are not mere recipients". Melalui implementasi model pembelajaran GI ini, diharapkan permasalahan proses belajar dan mengajar fisika yang dihadapi oleh guru dan siswa kelas Xd dapat direduksi secara bertahap.

Oleh karena itu, penelitian ini bertujuan untuk menjawab permasalah bagaimanakah merencanakan dan melaksanakan model pembelajaran koperatif tipe investigasi kelompok yang dapat meningkatkan efektifitas proses pembelajaran fisika di kelas $X_{d}$ SMA Negeri 6 Kota Bengkulu.

Menurut Mitchell, Montgomery, Holder and Start (2008), terdapat empat landasan filosofi pendidikan yang digunakan dalam penelitian ini untuk pemilihan model pembelajaran GI. Pertama, Dewey's Educational Philosophy; tujuan pendidikan adalah untuk mengembangkan masyarakat belajar secara sosial yang memahami bagaimana bekerja sama untuk menyelesaikan masalah dan membangun pengetahuan. Kedua, Group Dynamics; proses belajar dan penyelesaian masalah terjadi ketika siswa bekerja dalam kelompok. Ketiga, Constructivist Psychology of Cognition; pengetahuan diperoleh melalui interaksi antara siswa dengan siswa dan antara siswa dengan benda-benda nyata (Zingaro 2008). Terakhir, Motivation Theory; proses pembelajaran juga tergantung pada motivasi intrinsik.

Pembelajaran GI dicirikan oleh empat komponen utama "the four I's" yaitu Investigasi, Interaksi, Interpretasi dan Motivasi Instrinsik (Mitchell, Montgomery, Holder \& Start 2008). Investigasi menuntut siswa dalam kelompok fokus pada proses penyelidikan terhadap topik yang diminati. Interaksi sosial merupakan karakteristik dari metode pengajaran koperatif, yang mengharuskan siswa-siswa untuk menyelidiki ide-ide dan saling membantu dalam belajar. Interpretasi terjadi bila siswa dalam kelompok mensintesis dan memberikan penjelasan terhadap temuan-temuan kelompok untuk memperkaya pemahaman dan penjelasan ide-ide. Terakhir, motivasi intrinsik merupakan kekuatan pendorong dalam diri siswa dengan memberikan kesempatan pada siswa secara bebas dalam proses penyelidikan. Ciri-ciri utama pembelajaran GI ditampilkan secara sederhana pada diagram berikut ini. 


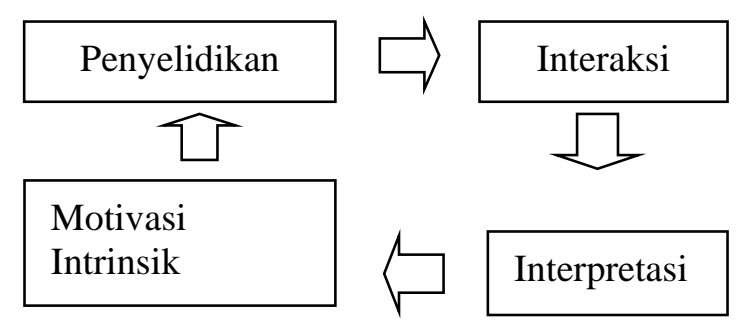

GAMBAR 1. Ciri-ciri Utama Pembelajaran GI.

Berdasarkan theoritical framework yang tunjukkan pada GAMBAR 1, pembelajaran koperatif tipe GI dapat diterapkan dalam pembelajaran fisika yang memiliki permasalahan belajar seperti "fisika sulit", "fisika membosankan", atau "fisika tidak menarik".

Pembelajaran koperatif tipe GI dilaksanakan dalam enam tahap seperti dalam TABEL 1 (Shachar \& Fischer 2004; Mitchell, Montgomery, Holder \& Start 2008). Tahap 1, guru menyajikan topik-topik yang dapat diselidiki dari berbagai aspek. Berdasarkan topik tersebut, siswa menentukan sub-topik yang ingin diselidiki. Kriterianya adalah topik yang dapat menimbulkan berbagai tanggapan dari seluruh siswa dalam bentuk permasalahan. Kemudian, siswa menentukan anggota kelompoknya berdasarkan kesamaan minat pada sub-topik yang dipilih.

TABEL 1. Tahap-Tahap Pembelajaran Group Investigation (GI)

\begin{tabular}{ll}
\hline Tahap & Kegiatan Pembelajaran \\
\hline Satu & Siswa menentukan sub-topik/ bahasan yang diselidiki dan membentuk kelompok berdasarkan kesamaan minat. \\
Dua & Siswa dalam kelompok merencanakan penyelidikan. \\
Tiga & Siswa dalam kelompok melaksanakan penyelidikan. \\
Empat & Siswa dalam kelompok merencanakan penyajian hasil penyelidikan. \\
Lima & Siswa dalam kelompok menyajikan hasil penyelidikan. \\
Enam & Guru bersama dengan siswa mengevaluasi hasil penyelidikan. \\
\hline
\end{tabular}

Setiap kelompok merencanakan langkah-langkah dan tujuan penyelidikan yang konsisten dengan sub-topik yang dipilih. Tahap II, siswa dalam kelompok merencanakan penyelidikan berdasarkan sub-topik yang disepakati oleh anggota kelompok. Tahap III adalah tahap penyelidikan yang dilakukan setiap kelompok dengan berdasarkan rencana yang telah dibuat bersama dalam kelompok. Peranan guru pada tahap ini yaitu untuk memonitor proses penyelidikan; memberikan bantuan bila diperlukan; menyarankan sumber-sumber informasi yang diperlukan; memastikan berbagai keterampilan proses digunakan pada saat penyelidikan. Tahap IV, kelompok merencanakan presentasi hasil penyelidikan. Dalam hal ini, peserta didik mengevaluasi hal-hal yang telah dipelajari, dan merangkum hasil penyelidikan menjadi suatu bentuk penyajian yang dapat dipahami oleh seluruh anggota kelas. Tahapan V, kelompok menyajikan hasil penyelidikan di depan anggota kelompok lainnya. TahapVI, guru dan siswa mengevaluasi penyajian dan diikuti dengan tanggapan kepada kelompok penyaji.

Agar penerapan pembelajaran GI sesuai dengan kondisi siswa Xd, tuntutan kurikulum (materi pelajaran, alokasi waktu) dan ketersedian sumber belajar (buku siswa, alat-alat lab.), maka modifikasi aktivitas belajar perlu dilakukan. Namun, enam tahapan pembelajaran GI masih diikuti.

Pada tahap 1, guru mengidentifikasi topik utama yang akan diselidiki oleh siswa dengan berpedoman pada kurikulum (KTSP) karena sekolah masih menerapkan KTSP. Berdasarkan analisis kurikulum, materi pelajaran terdiri dari suhu dan perpindahan kalor. Untuk mengeksplorasi topiktopik penyelidikan, guru mengajukan permasalahan "Apa saja yang dapat kita pelajari dari konsep suhu dan perpindahan kalor?" Melalui permasalahan ini, diharapkan seluruh siswa dapat memberikan berbagai tanggapan yang mengarahkan mereka untuk menentukan beberapa sub-topik. Disebabkan keterbatasan waktu (90 menit), peran guru pada tahap ini lebih dominan untuk mengarahkan dan menuntun siswa agar siswa dapat merumuskan permasalahan yang berkaitan dengan sub topik materi penyelidikan (TABEL 2). 
TABEL 2. Sub-Topik Materi dan Aktivitas Belajar

\begin{tabular}{|c|c|c|c|}
\hline \multirow{2}{*}{$\begin{array}{l}\text { Sub } \\
\text { Topik }\end{array}$} & \multicolumn{3}{|c|}{ Cakupan Materi Permasalahan } \\
\hline & $\begin{array}{c}\text { Pembiasaan } \\
\text { (Aktivitas) }\end{array}$ & $\begin{array}{c}\text { Siklus I } \\
\text { (Aktivitas) }\end{array}$ & $\begin{array}{c}\text { Siklus II } \\
\text { (Aktivitas) }\end{array}$ \\
\hline 1 & $\begin{array}{l}\text { Suhu \& termometer } \\
\text { (diskusi) }\end{array}$ & $\begin{array}{c}\text { Pemuaian zat cair } \\
\text { (diskusi) }\end{array}$ & $\begin{array}{c}\text { Prinsip Azas Black } \\
\text { (diskusi) }\end{array}$ \\
\hline 2 & $\begin{array}{l}\text { Skala termometer } \\
\text { (diskusi) }\end{array}$ & $\begin{array}{l}\text { Pemuaian gas } \\
\text { (diskusi) }\end{array}$ & $\begin{array}{l}\text { Kalorimeter } \\
\text { (percobaan) }\end{array}$ \\
\hline 3 & $\begin{array}{l}\text { Pemuaian panjang } \\
\text { (percobaan) }\end{array}$ & $\begin{array}{l}\text { Persamaan gas ideal } \\
\text { (diskusi) }\end{array}$ & $\begin{array}{c}\text { Aliran panaskonduksi } \\
\text { (percobaan) }\end{array}$ \\
\hline 4 & $\begin{array}{l}\text { Pemuaian luas } \\
\text { (diskusi) }\end{array}$ & $\begin{array}{c}\text { Kalor jenis dan kapasitas } \\
\text { (percobaan) }\end{array}$ & $\begin{array}{l}\text { Aliran panas konveksi } \\
\text { (percobaan) }\end{array}$ \\
\hline 5 & $\begin{array}{c}\text { Pemuaian volume } \\
\text { (diskusi) }\end{array}$ & $\begin{array}{c}\text { Perubahan wujud zat } \\
\text { (diskusi) }\end{array}$ & $\begin{array}{l}\text { Aliran panas radiasi } \\
\text { (diskusi) }\end{array}$ \\
\hline
\end{tabular}

Setelah ditentukan cakupan permasalahan (sub-topik), siswa dibimbing untuk membentuk lima kelompok yang terdiri dari enam siswa dalam satu kelompok karena ada lima sub-topik telah ditentukan. Disamping berdasarkan minat pada sub topik, anggota kelompok ditentukan oleh guru dengan berdasarkan kriteria kemampuan akademik (tinggi, sedang, rendah) dan jenis kelamin.

Modifikasi pada tahap II yaitu proses perencanaan dan penentuan langkah-langkah penyelidikan yang ditentukan oleh guru dalam bentuk lembar kerja siswa (LKS) dan lembar diskusi siswa (LDS). Disamping masalah waktu, keterbatasan kapasitas guru untuk membimbing 30 siswa ketika mereka merancang dan melaksanakan penyelidikan merupakan pertimbangan utama untuk memodifikasi tahap ini.

\section{METODE}

Penelitian tindakan kelas (PTK) model Kemmis (Tan, Sharan \& Lee 2003) diadopsi dan diterapkan untuk menjawab permasalahan penelitian sebagai upaya perbaikan yang bersifat kolaboratif dan reflektif antara guru fisika (guru pamong) dengan mahasiswa Praktek Kuliah Lapangan (PKL) dan dosen pembimbing. Pendekatan Mixed Method Research juga diterapkan dalam penelitian ini. Metode kuantitatif digunakan untuk menganalisis instrumen penelitian dan hasil belajar siswa. Sedangkan, metode kualitatifatif diterapkan untuk mendokumentasikan, mengidentifikasi dan memaknai peristiwa-peristiwa yang terjadi di kelas selama proses observasi pembelajaran berlangsung (Erickson 1998).

PTK dilakukan di kelas Xd SMAN 6 Kota Bengkulu tahun ajaran 2013/2014 dengan jumlah 30 siswa. Penentuan sekolah dan kelas didasarkan pada prinsip kemudahan untuk memperoleh akses ke sekolah, kesediaan guru dan siswa dalam pelaksanaan PTK serta lokasi pelaksanaan PKL II. Sekolah ini termasuk salah satu sekolah favorit di Kota Bengkulu (Akreditasi A) sehingga seleksi penerimaan siswa relatif ketat.

Sebanyak 22 butir tes disusun oleh tim peneliti dan diuji cobakan pada 60 siswa kelas $\mathrm{X} a$ dan $\mathrm{X} b$ SMAN 6 Kota Bengkulu. Uji validitas butir tes terdiri dari uji validitas isi, konstruksi dan empiris. Validitas isi dilakukan dengan menyusun butir tes sesuai dengan indikator/tujuan pembelajaran dan level kognitif C2 (11 butir tes), C3 (7 butir tes) dan C4 (4 butir tes) menurut Taxonomi Bloom yang diuraikan dalam matriks. Uji validitas konstruksi butir tes ditentukan melalui uji konsistensi penilaian (koefisien ICC) oleh dua panelis. Uji validitas empiris ditentukan melalui corrected item-total correlation dan uji reliabilitas diketahui melalui koefisien Alpha Cronbach. Pengolahan data untuk analisis butir tes menggunakan SPSS versi 17.

Berbagai metode dan instrumen penelitian digunakan: (a) tes tertulis untuk mengetahui capaian hasil belajar/kompetensi pada akhir setiap siklus, (b) lembar observasi aktivitas guru untuk mengetahui konsistensi pelaksanaan proses pembelajaran dengan skenario pembelajaran, (3) jurnal harian untuk refleksi guru, dan (4) LKS/LDS untuk siswa selama penyelidikan berlangsung. Semua 
sumber data digunakan untuk memperoleh validitas internal data hasil penelitian melalui metode triangulasi data.

Fase asimilasi (pembiasaan) model GI dilakukan di kelas $\mathrm{Xd}$ yang bertujuan untuk memperkenalkan strategi pengajaran yang relatif baru bagi siswa-siswa. Berdasarkan karateristik model pembelajaran GI, peserta didik dituntut untuk beralih peran dari (a) penerima informasi menjadi penemu informasi, (b) belajar secara individu menjadi belajar berkelompok, dan (c) belajar yang diarahkan oleh guru menjadi belajar mandiri (self-directed learners) (Zingaro 2008). Demikian juga halnya dengan peran guru; disamping sebagai sumber informasi, juga berperan sebagai pembimbing, konsultan, dan manager kelas (Mitchell, Montgomery \& Stuart 2008).

Perubahan ini jelas berpengaruh pada proses belajar dan proses interaksi sosial selama proses pembelajaran berlangsung. Oleh karena itu, informasi yang diperoleh pada fase asimilasi digunakan oleh tim peneliti untuk merancang pembelajaran GI (modifikasi) agar pengajaran efektif dapat diwujudkan. Proses asimilasi ini diharapkan terjadi antara model pembelajaran GI dengan kondisi siswa (gaya belajar, lingkungan belajar) karena belum ada publikasi penelitian yang dapat mengidentifikasi strategi pengajaran yang dapat diikuti oleh setiap individu siswa. Dalam hal ini, Marzano (2007) menyatakan bahwa "...teachers must determine which strategies to employ with the right students at the right time" (p. 3).

\section{HASIL DAN PEMBAHASAN}

Deskripsi hasil penelitian dan pembahasannya meliputi uji coba instrumen dan analisis butir tes, proses pembiasan pembelajaran GI (modifikasi), dan pelaksanaan tindakan siklus I dan II yang terdiri dari pelaksanaan tindakan, pengamatan, refleksi, dan perencanaan ulang.

Data penelitian primer diperoleh dari hasil tes pada setiap akhir siklus. Tes pilihan ganda dengan empat alternatif pilihan jawaban digunakan untuk mengetahui hasil belajar. Berdasarkan uji panelis, diperoleh bahwa koefisien ICC sebesar 8,3 (sangat baik) (Smith 2003). Nilai ini dimaknai bahwa kedua panelis memberikan penilaian yang konsisten terhadap kontruksi butir tes. Dari hasil uji validitas butir tes, diketahui bahwa 8 butir tes (siklus I) kategori valid $(>0,51)$ dan 8 butir tes (siklus II) juga valid $(>0,62)$. Uji reliabilitas butir tes diketahui bahwa koefisien Alpha Cronbach untuk 8 butir tes siklus 1 adalah 0,79 dengan nilai 0,81 (tertinggi) dan 0,79 (terendah) sedangkan 8 butir tes siklus II adalah 0,84 dengan nilai 0,87 (tertinggi) dan 0,81 (terendah). Sehingga koefisien reliabilitas 16 butir tes telah memenuhi persyaratan $(>0,70)$ sebagai instrumen penelitian (Smith 2003).

Oleh karena, proses pembelajaran GI relatif berbeda dengan sebelumnya, guru menginformasikan bagaimana pelaksanaan pembelajaran GI kepada seluruh siswa. Namun, mayoritas siswa (85\%) memberikan 'resistensi' melalui pernyataan: "Pak, kami tidak pernah melakukan seperti ini!", "Biasanya kami mengerjakan soal-soal pak?". Tindakan yang dilakukan guru adalah memberikan pemahaman tentang "mengapa dan bagaimana" pembelajaran GI dilakukan dan menjelaskan kelebihan dari model pembelajaran GI serta mengajak semua siswa berpartisipasi secara aktif.

Secara umum, pelaksanaan pembelajaran pada fase asimilasi telah mengikuti tahapan pembelajaran GI sebagaimana dinyatakan oleh ketiga pengamat. Namun, berdasarkan hasil refleksi, tiga tahapan pelaksanaan GI perlu dicermati oleh guru. Pada tahap perencanaan dan penyelidikan, guru belum dapat memberikan membimbing secara maksimal dan terarah. Karena guru berpindah ke kelompok lain sebelum kelompok yang bertanya memahami bagaimana melakukan penyelidikan. Tahap presentasi hasil belum terselenggara secara efektif dalam hal manajemen waktu dan pembagian peran setiap anggota kelompok. Guru belum menetapkan alokasi waktu penyampaian hasil kerja kelompok dan belum ditentukan anggota kelompok sebagai juru bicara. Pelaksanaan tahap evaluasi hasil penyelidikan masih cenderung didominasi oleh guru sehingga siswa belum dapat berpartisipasi aktif untuk memberikan pendapat/ide-ide.

Fase pelaksanaan tindakan yang telah dilaksanakan terdiri dari dua siklus. Indikator keberhasilan tindakan kedua siklus adalah capaian daya serap dan ketuntasan belajar. Kriteria ketuntasan belajar klassikal yang digunakan adalah minimal $85 \%$ dari jumlah siswa telah menguasai $75 \%$ materi yang telah dipelajari. Sedangkan kriteria daya serap klasikal ditentukan dari jumlah nilai seluruh siswa dibagi dengan hasil perkalian jumlah siswa dengan nilai ideal 
Pelaksanaan tindakan di siklus I dilakukan pada tanggal 10 April 2014 selama 90 menit yang diikuti oleh 30 siswa. Secara umum, tahapan pembelajaran telah dilakukan oleh guru dengan berpedoman pada RPP dan skenario pembelajaran yang mencakup enam tahap pembelajaran GI (TABEL 1). Namun, guru belum dapat berperan sebagai fasilitator dan meneger dalam kegiatan proses penyelidikan sehingga siswa tidak dapat melaksanakan penyelidikan sesuai LKS dan LDS. Misalnya, siswa pada subtopik 4 tidak dapat melakukan eksperimen dengan efektif karena KIT yang digunakan tidak dapat beroperasi dengan sempurna. Kondisi ini menyebabkan guru banyak mengalokasikan waktunya untuk membantu siswa pada kelompok yang bermasalah dalam belajar. Akibatnya, kelompok lain kurang dapat diperhatikan oleh guru khususnya dalam pelaksanaan penyelidikan meskipun setiap kelompok telah diberikan panduan penyelidikan dalam bentuk LKS atau LDS.

Berdasarkan rangkuman hasil observasi oleh tiga pengamat ( $\mathrm{ICC}=0,54$ dan $\mathrm{SE}=0,2)$, aktivitas belajar siswa yang sesuai dengan ciri utama pembelajaran GI (Gambar 1) belum dapat ditampilkan oleh siswa. Ketika melakukan penyelidikan, secara rata-rata dua siswa dalam setiap kelompok yang aktif melakukan kegiatan penyelidikan baik melalui kegiatan percobaan atau diskusi. Sedangkan siswa lainnya melakukan kegiatan yang sifatnya off-task seperti memainkan handpone (HP), mengobrol, berjalan hilir mudik, duduk dan diam tanpa berbuat apa-apa, dan mengerjakan tugas mata pelajaran lain, duduk diam dan lipat tangan.

Akibat sifat pasif ini, interaksi sosial yang terjadi antar anggota dalam setiap kelompok tidak sesuai dengan komponen kedua pembelajaran GI. Meskipun, guru selalu menegaskan bahwa pentingnya partisipasi aktif setiap anggota kelompok ketika mendatangi setiap kelompok. Oleh sebab itu, ketiga pengamat sepakat menyatakan bahwa interaksi yang terjadi baik pada tahap penyelidikan dan tahap merencanakan penyajian hasil penyelidikan lebih didominasi oleh siswa-siswa tertentu. Fakta ini tidak mencirikan cooperative learning yaitu (a) tidak ada kompetisi antar anggota kelompok, (b) tidak ada dominasi oleh anggota kelompok tertentu dan (3) keterlibatan anggota kelompok untuk mendorong terjadi proses pembelajaran pada semua anggota kelompok bukan sebaliknya (Mitchell, Montgomery, Holder \& Stuart 2008). Dampak berikutnya adalah proses interpretasi (komponen ketiga GI) hasil penyelidikan via diskusi kelompok dan proses berbagi ide/pendapat untuk merumuskan hasil penyelidikan belum terjadi hampir pada semua kelompok.

Oleh karena itu, aktivitas belajar pada siklus I belum dapat menumbuhkan motivasi intrinsik siswa (komponen keempat GI) terhadap kegiatan belajar yang dirancang secara kolaboratif oleh tim peneliti. Karena aktivitas belajar yang ditampilkan setiap kelompok melalui proses inkuiri bukan merupakan proses interaksi sosial dan hasil pemikiran bersama dari setiap anggota kelompok. Menurut Sharan and Sharan dalam Shachar and Fischer (2004), capaian aktivitas belajar sebagai tujuan kelompok yang diperoleh melalui interaksi sosial dan pemikiran bersama akan menumbuhkan motivasi intrinsik dari setiap anggota kelompok.

Disamping pengamatan aktivitas siswa selama proses pembelajaran, efektifitas pembelajaran GI dievaluasi melalui tes siklus I yang dilakukan pada akhir pertemuan (15 menit). Rangkuman data hasil tes siklus I ditampilkan pada TABEL 3. Berdasarkan TABEL 3 diketahui bahwa mayoritas (>77\%) siswa dapat menjawab soal dengan benar kecuali butir soal nomor $8(66,7 \%)$. Sehingga kriteria ketuntas belajar klasikal 86,7\% (>85\%) dan daya serap klassikal 81,9\% (>75\%) yang ditetapkan oleh sekolah dapat dicapai (lihat TABEL 4). Atau secara klassikal siswa mencapai ketuntasan belajar untuk lima sub-topik pada TABEL 2. Meskipun demikian, aktivitas belajar yang mengikuti model pembelajaran GI masih perlu ditingkatkan pada siklus II. Perencanaan ulang pembelajaran GI yang berdasarkan ciri utama GI perlu dilakukan dengan menggunakan informasi dari hasil refleksi tim peneliti pada siklus I.

Refleksi yang dilakukan oleh tim untuk perbaikan pada siklus II adalah (1) menjelaskan kembali aktivitas belajar menurut GI, terutama peran dan tanggung jawab setiap anggota kelompok karena keberhasilan kelompok tergantung pada keberhasilan kerja dari setiap anggota kelompok (Johnson \& Johnson 2002); (2) penambahan jumlah LKS/LDS untuk setiap kelompok, (2) penentuan anggota kelompok diberikan kebebasan kepada siswa dengan berdasarkan minat pada subtopik yang ingin diselidiki, (3) Memastikan semua alat (KIT) beroperasi, dan (4) Menyediakan berbagai sumber informasi; buku teks, internet, dan buku lain yang relevan. 
Pembelajaran Siklus II dilaksanakan pada 21 April 2014 (90 menit) di Lab. Fisika. Pada kegiatan awal, guru menjelaskan tujuan belajar yang hendak dicapai. Selama kegiatan inti, siswa dalam kelompok bekerjasama untuk mengumpulkan informasi/data-data hasil penyelidikan melalui eksperimen atau diskusi, menganalis dan menginterpretasi informasi yang diperoleh, serta merangkum ide/pendapat dari setiap anggota kelompok menjadi suatu hasil pemikiran bersama. Evaluasi dilakukan pada kegiatan penutup selama 10 menit. Skenario pembelajaran pada siklus II memberikan penekanan pada empat temuan utama pada siklus I. Perbaikan tindakan pada siklus ini telah memberikan perubahan yang signifikan pada aktivitas belajar siswa sehingga jumlah siswa yang berpartisipasi aktif relatif meningkat (76\%).

TABEL 3. Rangkuman Data Tes Belajar Siklus I dan II

\begin{tabular}{ccccccccc}
\hline \multirow{2}{*}{$\begin{array}{c}\text { No } \\
\text { Soal }\end{array}$} & \multicolumn{3}{c}{ Frekuensi (\%) Pilihan Jawaban Siswa } & \multicolumn{3}{c}{ Frekuensi (\%) Pilihan Jawaban Siswa } \\
& \multicolumn{3}{c}{ Siklus I (N=30) } & & \multicolumn{3}{c}{ Siklus II (N=30) } \\
\cline { 2 - 8 } & A & B & C & D & A & B & C & D \\
\hline 1 & $1(3,3)$ & $1(3,3)$ & $27(90,0)^{*}$ & $1(3,3)$ & $4(13,3)$ & $25(83,3)^{*}$ & $1(3,3)$ & $0(0,0)$ \\
2 & $24(80,0)^{*}$ & $1(3,3)$ & $2(6,7)$ & $3(10,0)$ & $7(23,3)$ & $7(23,3)$ & $13(43,3)^{*}$ & $3(10,0)$ \\
3 & $25(83,3)^{*}$ & $2(6,7)$ & $0(0,0)$ & $3(10,0)$ & $1(3,3)$ & $0(0,0)$ & $0(0,0)$ & $29(96,7)^{*}$ \\
4 & $1(3,3)$ & $26(86,7)^{*}$ & $1(3,3)$ & $2(6,7)$ & $0(0,0)$ & $25(83,3)^{*}$ & $4(13,3)$ & $1(3,3)$ \\
5 & $1(3,3)$ & $2(6,7)$ & $25(83,3)^{*}$ & $2(6,7)$ & $1(3,3)$ & $0(0,0)$ & $2(6,7)$ & $27(90,0)^{*}$ \\
6 & $1(3,3)$ & $2(6,7)$ & $4(13,3)$ & $23(76,7)^{*}$ & $0(0,0)$ & $0(0,0)$ & $28(93,3)^{*}$ & $2(6,7)$ \\
7 & $2(6,7)$ & $3(10,0)$ & $2(6,7)$ & $23(76,7)^{*}$ & $1(3,3)$ & $0(0,0)$ & $30(100,0)^{*}$ & $0(0,0)$ \\
8 & $20(66,7)^{*}$ & $5(16,6)$ & $2(6,7)$ & $3(10,0)$ & $1(3,3)$ & $2(6,7)$ & $0(0,0)$ & $27(90,0)^{*}$ \\
\hline Cat
\end{tabular}

Catatan: * Jawaban Benar

Ketiga pengamat yang mengobservasi proses pembelajaran pada siklus II sepakat (ICC $=0,71$; SE $=0,24)$ menyatakan bahwa pembelajaran GI telah dilaksanakan oleh guru sesuai dengan RPP dan skenario pembelajaran. Penilaian oleh pengamat juga menyatakan bahwa aktivitas belajar yang dilakukan siswa relatif sesuai dengan ciri utama pembelajaran GI meskipun pada tahap keenam GI masih cenderung didominasi oleh guru dan pemanfaatan waktu belum efektif. Setelah guru bersama siswa mengevaluasi hasil penyelidikan, 30 siswa mengerjakan 8 soal pilihan ganda yang telah divalidasi sebelumnya untuk mengetahui dampak pelaksanaan tindakan siklus 2 . Rangkuman hasil tes disajikan pada TABEL 3.

Berdasarkan TABEL 4, indikator kinerja tindakan telah tercapai yang mencakup daya serap $(85,5 \%)$ dan ketuntasan belajar klasikal $(100 \%)$, namun guru perlu melakukan pengajaran remedial pada pertemuan berikutnya untuk sub-materi radiasi karena hanya $43 \%$ siswa yang dapat menjawab dengan benar soal no.2 dengan benar (lihat TABEL 3). Kemampuan 30 siswa memahami materi pelajaran pada pokok bahasan suhu dan perpindahan panas mengalami peningkatan dari siklus $\mathrm{I}(\mathrm{M}=$ $81,9 ; \mathrm{SD}=8,30)$ ke siklus II $(\mathrm{M}=85,50 ; \mathrm{SD}=6,25)$.

TABEL 4 . Rangkuman Data Hasil Belajar Siklus I dan II

\begin{tabular}{|c|c|c|c|c|c|c|}
\hline \multirow[b]{2}{*}{ Siklus } & \multicolumn{6}{|c|}{ Data Deskriptif Hasil Belajar $(\mathrm{N}=30)$} \\
\hline & Nilai Min. & Nilai Mak. & $\begin{array}{c}\text { Rerata } \\
(\mathrm{M})\end{array}$ & $\begin{array}{c}\text { Stand. Deviasi } \\
\text { (SD) }\end{array}$ & $\begin{array}{l}\text { D.S } \\
(\%)\end{array}$ & $\begin{array}{c}\text { K.B.K } \\
(\%)\end{array}$ \\
\hline I & 67,75 & 94,00 & 81,89 & 8,30 & 81,89 & 86,67 \\
\hline II & 76,50 & 98,00 & 85,50 & 6,25 & 85,50 & 100,00 \\
\hline
\end{tabular}

Ket. DS (Daya Serap); KBK (Ketuntasan Belajar Klassikal).

\section{PENUTUP}

Perencanaan dan pelaksanaan model pembelajaran koperatif tipe GI (Group Investigation) yang dimodifikasi dapat meningkatkan efektifitas proses pembelajaran fisika di kelas $X_{d}$ SMA N 6 Kota Bengkulu jika ditinjau dari capaian daya serap dan ketuntasan belajar klasikal. Hal ini sejalan dengan 
pendapat Foley and O'Donnel (2002) bahwa capaian akademik yang diperoleh siswa melalui model koperatif tipe GI lebih maksimal dari pengajaran dengan metode tradisional (ceramah/diskusi, pemecahan soal-soal). Modifikasi tahap pembelajaran I dan II GI dilakukan untuk menyesuaikan dengan kondisi siswa, guru, dan tuntutan kurikulum agar capaian tujuan pembelajaran dapat dimaksimalkan. Pelaksanaan asimilasi (pembiasaan) sebelum pelaksanaan model pembelajaran koperatif tipe GI yang telah dilakukan dapat membantu siswa dan guru untuk beradaptasi pada strategi belajar dan mengajar yang relatif baru yang menuntut peran aktif siswa dalam proses pembelajarannya. Peranan guru sebagai fasilitator dan manejer khusus pada tahap melaksanakan penyelidikan merupakan faktor penentu keberhasilan penerapan model pembelajaran koperatif tipe GI pada pembelajaran Fisika pada materi pelajaran Suhu dan Perpindahan kalor di kelas Xd SMA Negeri 6 Kota Bengkulu.

\section{UCAPAN TERIMAKASIH}

Kami mengucapkan terimakasih kepada seluruh siswa kelas X-d SMA Negeri 6 Kota Bengkulu yang terlibat langsung dalam penelitian ini. Tanpa partisipasi mereka, penelitian dan laporan ini tidak akan terwujud. Kemudian, ucapan terimakasih juga diucapkan kepada Vera Anggreani, M.Pd.Si (sebagai guru pamong dan pengamat 2), dan Abdal Khairi S, S.Pd (sebagai Kepala Sekolah dan pengamat 3) atas peran sertanya dalam penelitian ini, serta Drs. Indra Sakti, M.Pd (sebagai teman sejawat) atas kritik dan sarannya selama pelaksanaan tindakan berlangsung.

\section{REFERENSI}

Erickson, F, “Qualitative research methods for science education”. In B. J. Fraser \& K. Tobin (Eds), International handbook of sience education, (Dorrecht, The Netherlands, 1998), pp. 1155-1157.

Foley, K., \& O'Donnell, A. 2002, 'Cooperative learning and visual organizers: Effects on solving mole problems in high school chemistry', Asian-Pasific Journal of Education, vol. 22, pp. 38-51.

Johnson, D. \& Johnson, R. 2002, 'Learning together and alone: Overview and mata-analysis', Asia Pasific Journal of Education, vol.22, pp. 95-105.

Marzano, R..J. "The art and science of teaching: A comprehensive framework for effective instruction". (Association for Supervision and Curriculum Development Alexandria, USA, 2007), pp. 3-4.

Mitchell, M.G, Montgomery, H, Holder, M \& Stuart, D 2002, 'Group investigation as cooperative learning strategy: An integrated analysis of the literature', The Alberta Journal of Educational Research, vol. 32, pp. 388-395.

Rusman. "Model - Model Pembelajaran”. (PT Raja Grafinda Persada, Jakarta, 2011), pp. 5-6.

Shachar, H \& Fischer, S 2004, 'Cooperative learning and the achievement of motivation and perception of students in 11th grade chemistry classess', International Journal of Science Education, vol. 14, pp. 69-87.

Smith, J.K 2003, 'Reconsidering reliability in classroom asessment and grading, Educational' Measurement: Issues and Practice, vol. 22, pp. 26-33.

Tan, I., Sharan, S., \& Lee, C. "Group Investigation and Student Learning: An the action Research Planner". (Springer, The Nederlands, 2003).

Zingaro, D. "Group Investigation: Theory and Practice", (Ontario Institute for Studies in Education, Toronto, 2008), pp. 1-8. 